\title{
What can predict and prevent the long-term use of benzodiazepines?
}

\author{
Takeo Hata ${ }^{\text {a, b, *, Tetsufumi Kanazawa }}{ }^{\text {c, d, e }}$, Takeshi Hamada ${ }^{\text {a }}$,Masami Nishihara ${ }^{a}$, Ashley Ian Bush ${ }^{\text {d, e, }}$ \\ Hiroshi Yoneda ${ }^{\mathrm{c}}$, Miki Nakajima ${ }^{\mathrm{b}}$, Takahiro Katsumata ${ }^{\mathrm{a}}$ \\ a Department of Pharmacy, Osaka Medical College Hospital, 2-7 Daigaku-machi, Takatsuki, Osaka 569-8686, Japan \\ b Drug Metabolism and Toxicology, Faculty of Pharmaceutical Sciences, Kanazawa University, Kakuma-machi, Kanazawa, Ishikawa 920-1192, Japan

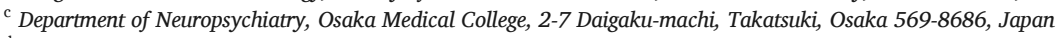 \\ d Department of Psychiatry, The University of Melbourne, VIC 3010, Australia \\ e Melbourne Dementia Research Centre, The Florey Institute of Neuroscience and Mental Health, 30 Royal Parade, Parkville, VIC 3052, Australia
}

\section{A R T I C L E INFO}

\section{Keywords:}

Benzodiazepines (BZDs)

Long-term use

Sleep medicine

Pharmacy

Psychiatry

Retrospective survey

\begin{abstract}
A B S T R A C T
Although benzodiazepines (BZDs) are commonly prescribed for insomnia or anxiety, long-term use of BZDs causes serious adverse effects such as daytime drowsiness and cognitive decline. In the current study, we evaluated the predictors and preventers of long-term usage of BZDs from a retrospective survey by utilizing the 12-year prescription record of a university hospital. From the prescription data of 92,005 people, users of BZDs ( $\mathrm{n}=3,470$, male $=39.2 \%$, mean age $=60 \pm 17.5$ ) were analyzed. During this period, both the number of prescriptions (2722 in 2004 to 1019 in 2016) and the number of BZDs (1.73 in 2004 to 1.36 in 2016) gradually decreased, although more than half of the patients continued to take BZDs for over three years. High risk factors for long-term use of BZDs include elderly patients ( $>65$ years old), high dosage ( $>5 \mathrm{mg}$ diazepam per day), psychiatrist-prescribers, and users with polytherapy. Discontinuation is significantly found in users of hypnotic BZDs and alternative psychotropic medical drugs (including antipsychotics, serotonergic drugs, or newer types of sleep medicine). Future studies should focus on elucidating interventions that are more effective against long-term usage of BZDs.
\end{abstract}

\section{Introduction}

Benzodiazepines (BZDs) have been widely prescribed in clinical practice around the world for over four decades to treat various disorders (Charlson et al., 2009). BZDs have been used for conditions including insomnia, anxiety, panic disorder, muscle spasticity, and various mental disorders (Cloos and Ferreira, 2009; Fisher et al., 2012). Although all BZDs have very similar mechanisms of action, specific BZDs are used for specific purposes, as they differ based on the duration of action, metabolic half-life, and the presence/absence of psychotropically active metabolites (Lader, 2011).

It has been well-documented that the use of BZDs presents potentially serious adverse effects, including daytime drowsiness, light-headedness, ataxia, psychomotor disturbance, and anterograde amnesia (Barker et al., 2004; Holbrook et al., 2000). Especially in the elderly, a relationship between BZD use and an increased risk of road traffic accidents (Smink et al., 2010), falls, fractures (Cumming and Le Couteur,
2003), and cognitive decline (Shorr and Robin, 1994), as well as socioeconomic costs (Panneman et al., 2003) has been described. A nested, case-control study estimating the impact of injurious falls associated with BZDs in a population of elderly persons reported a statistically significant risk of serious falls (Pariente et al., 2008).

Although short-term use of BZDs is considered safe and effective (Martin et al., 2007; Pfeiffer et al., 2011), various studies suggest that long-term use may be harmful. Long-term use carries the risk of dependence, withdrawal syndrome, cognitive impairment, diminishing effect, tolerance, and difficulty in discontinuing treatment (Charlson et al., 2009; Lader, 2011; Lader and Petursson, 1981). Some patients may experience withdrawal symptoms such as rebound insomnia and anxiety after only 2-4 weeks of treatment (Urru et al., 2015). Receiving hypnotic prescriptions is also associated with excess mortality (Belleville, 2010) and cancer incidence (Kripke et al., 2012).

In response to these risks, although several international clinical guidelines and expert consensus statements have been published that recommend limiting the long-term use of BZDs, especially in older pa-

\footnotetext{
* Corresponding author. Department of Pharmacy, Osaka Medical College Hospital, 2-7 Daigaku-machi, Takatsuki, Osaka 569-8686, Japan.

Email address: phc033@osaka-med.ac.jp (T. Hata)
} 
tients (American Geriatrics Society 2012 Beers Criteria Update Expert Panel, 2012; McLeod et al., 1997), the prevalence of long-term use remains widespread (Vicens et al., 2014). Thus, reducing the long-term use of BZD is an important worldwide issue.

Many studies have been performed to identify the prevalence and risk factors of long-term BZD use. Older age has been found to be a significant factor in predicting the continuation of BZD use (Luijendijk et al., 2008; Manthey et al., 2011). Patients who may have previously used BZDs tend to become long-term BZD users. The quantity of BZD used is also a strong predictor of long-term use (Kjosavik et al., 2012), whereas the impact of factors such as lower level of education (Manthey et al., 2011) and sex (Taipale et al., 2015) is still controversial. Although psychiatric history, such as anxiety, tension, schizophrenia, bipolar disorder, depression, and Alzheimer's disease, are positively associated with BZD continuation (Manthey et al., 2011; Taipale et al., 2015), concurrent use of antipsychotics and mood stabilizers is significantly associated with BZD discontinuation (Veronese et al., 2007).

Several alternative medications to BZDs are prescribed for psychiatric conditions. Quetiapine is approved and marketed in many countries for schizophrenia, and is commonly used off-label for the treatment of insomnia and anxiety in older adults, owing to its sedative properties when used at low doses (Iaboni et al., 2016). Trazodone, a serotonin antagonist and reuptake inhibitor used for depressive disorders, is also prescribed off-label for the treatment of these conditions (Bossini et al., 2015; Iaboni et al., 2016).

Furthermore, a new class of hypnotics has recently begun to be distributed in Japan. Ramelteon, a selective melatonin receptor type 1 and 2 (MT1/MT2) agonist, was approved in 2010 to treat sleep disorders; it has a good safety profile. Ramelteon has no measurable affinity for a large number of ligand binding sites (including BZD receptors, dopamine receptors, opiate receptors) associated with cognitive impairment, dependence, and withdrawal effects (Kato et al., 2005). Suvorexant, an orexin receptor antagonist, has also been available since 2014, and was found to be well tolerated in clinical trials, with some mild adverse effects (Schroeck et al., 2016). Rebound or withdrawal symptoms were not observed with the discontinuation of suvorexant (Schroeck et al., 2016).

These alternative hypnotics may effectively prevent the long-term use of BZDs while maintaining good sleep quality. Nevertheless, little information is available about the effects of alternative hypnotics on reducing or discontinuing BZD use. Recently, a study based on a nationwide claims-database identified that concurrent use of antipsychotic drugs was a predictor of long-term BZD use. However, the limitation of this study was that the cohort analyzed included very few people that were 75 years old and above, because the analyzed claims-database primarily consisted of corporate employees (Takeshima et al., 2016). Therefore, the current study aimed to describe the tendency to prescribe BZDs in the last 12 years, and to elucidate the predictors of BZD discontinuation in an extended age group of patients, who were prescribed BZDs in our university hospital located in a city area, using data derived from an electronic health-record database.

\section{Methods}

\subsection{Data source}

We used accounting data from the medical accounting system during the period from March 2004 to September 2016 to analyze BZD prescription tendencies for psychiatric patients in the past 12 years, and the prescription data from the electronic health record during the period from January 2012 to September 2016 for describing the predictors of BZD continuation in our university hospital. The hospital serves as a general hospital for the city of Takatsuki (population: 350,000) in Osaka. It has 882 beds and 29 clinical departments including the Department of Psychiatry. This study was approved by the ethics committee of Osaka Medical College (Approval ID: RIN-486, 2160).

\subsection{Study population}

To describe the tendency to prescribe BZDs using the medical accounting data, we used the data of outpatients from the Department of Psychiatry. To describe the predictors of BZD continuation using the prescription data, we defined the following inclusion criteria: age older than 18 years, outpatients of all clinical departments, oral administration, no BZD prescription in the last year or more in order to adopt to the new user design. We included drugs approved for medical prescription in Japan coded as N03A, N05B, and N05C, according to the Anatomical Therapeutic and Chemical (ATC) classification system (Table 1).

\subsection{Continuation of BZD use}

Similar to previous reports, we defined BZD continuation as the receipt of at least one prescription for BZD within three months (Ishigooka et al., 1998; Takeshima et al., 2016). The three-month time window was chosen because the prescription of BZDs is restricted to once per 30 or 90 days in Japan, depending on the product (Takeshima et al., 2016).

\subsection{Potential predictors of BZD continuation}

We investigated the following potential predictors: sex, age (18-45, 45-65, 65-85, >85), medical specialty (psychiatrist-prescriber or non-psychiatrist-prescriber) (Takeshima et al., 2016), dosage of BZD [diazepam (DZP) equivalent daily dose (Inada and Inagaki, 2015); $\leq 5 \mathrm{mg}$, $5 \mathrm{mg}<$ ], concurrent use of BZD (monotherapy, polytherapy), indication of initial prescription (only at bedtime, others), duration of initial prescription ( $<21$ days, $\geq 21$ days), half-life of initial BZD [ultra-short ( $<6 \mathrm{~h}$ ), short (6-12 h), medium (12-24 h), or long ( $>24 \mathrm{~h})$ ] (Passaro et al., 2000), type of BZD (hypnotic, anxiolytic, others), and concurrent psychotropic drugs (antidepressant, antipsychotics, or alternative drug to BZD).

In case of patients who had visited doctors from multiple clinical departments including psychiatry, we assigned them to a psychiatrist-prescriber. Note that the psychiatry department in our hospital sees various psychiatric patients, including those with a diagnosis of schizophrenia, depression, bipolar disorder, dementia, anxiety disorder, and so on. We converted the total BZD daily dose into a DZP equivalent according to Inada et al. (Inada and Inagaki, 2015), and a maximal dosage of DZP-equivalent dose in the observation period was chosen as the dosage of BZD. We referred to package inserts and booklets, also known as interview forms, prepared by the manufacturers, to obtain the information regarding the half-life of the particular BZD. When patients used more than one BZD with different half-lives, the BZD with the longest half-life was chosen (Takeshima et al., 2016). When patients received both a hypnotic and an anxiolytic, we assigned them to both the hypnotic and anxiolytic groups to define the type of BZD. Alternative drugs to BZD that were analyzed in this study are listed in Table 2.

\subsection{Statistical analysis}

The Kaplan-Meier event-free curve was employed to calculate the event-free probability. Multivariate Cox regression analysis was used to explore independent predictors associated with the time-to-event. The event was the discontinuation of BZD prescription. When the participants were not prescribed BZD during the course of three months, we took the month of the last BZD prescription as the BZD discontinuation date (Takeshima et al., 2016). Variance inflation factors (VIF) of 10 or 
Table 1

The 31 benzodiazepines analyzed in this study.

\begin{tabular}{|c|c|c|c|}
\hline Benzodiazepines & $\begin{array}{l}\text { Diazepam } \\
\text { equivalent dose } \\
\text { (mg) }\end{array}$ & Half-life & Type \\
\hline Tofisopam & 125 & $\begin{array}{l}\text { Ultra } \\
\text { short } \\
(<6 \mathrm{~h})\end{array}$ & Others \\
\hline Triazolam & 0.25 & $\begin{array}{l}\text { Ultra } \\
\text { short } \\
(<6 \mathrm{~h})\end{array}$ & Hypnotic \\
\hline Zolpidem Tartrate & 10 & $\begin{array}{l}\text { Ultra } \\
\text { short } \\
(<6 \mathrm{~h})\end{array}$ & Hypnotic \\
\hline Zopiclone & 7.5 & $\begin{array}{l}\text { Ultra } \\
\text { short } \\
(<6 \mathrm{~h})\end{array}$ & Hypnotic \\
\hline Alprazolam & 0.8 & $\begin{array}{l}\text { Short } \\
(6-12 \mathrm{~h})\end{array}$ & Anxiolytic \\
\hline Brotizolam & 0.25 & $\begin{array}{l}\text { Short } \\
(6-12 \mathrm{~h})\end{array}$ & Hypnotic \\
\hline Clotiazepam & 10 & $\begin{array}{l}\text { Short } \\
(6-12 \mathrm{~h})\end{array}$ & Anxiolytic \\
\hline Eszopiclone & 2.5 & $\begin{array}{l}\text { Short } \\
(6-12 \mathrm{~h})\end{array}$ & Hypnotic \\
\hline Etizolam & 1.5 & $\begin{array}{l}\text { Short } \\
(6-12 \mathrm{~h})\end{array}$ & Others \\
\hline Lormetazepam & 1 & $\begin{array}{l}\text { Short } \\
(6-12 \text { h) }\end{array}$ & Hypnotic \\
\hline $\begin{array}{l}\text { Rilmazafone } \\
\text { Hydrochloride } \\
\text { Hydrate }\end{array}$ & 2 & $\begin{array}{l}\text { Short } \\
(6-12 \mathrm{~h})\end{array}$ & Hypnotic \\
\hline Amobarbital & 50 & $\begin{array}{l}\text { Medium } \\
(12-24 \mathrm{~h})\end{array}$ & Hypnotic \\
\hline Bromazepam & 2.5 & $\begin{array}{l}\text { Medium } \\
(12-24 \mathrm{~h})\end{array}$ & Anxiolytic \\
\hline Estazolam & 2 & $\begin{array}{l}\text { Medium } \\
(12-24 \mathrm{~h})\end{array}$ & Hypnotic \\
\hline Flunitrazepam & 1 & $\begin{array}{l}\text { Medium } \\
(12-24 \mathrm{~h})\end{array}$ & Hypnotic \\
\hline Lorazepam & 1.2 & $\begin{array}{l}\text { Medium } \\
(12-24 \mathrm{~h})\end{array}$ & Anxiolytic \\
\hline Nitrazepam & 5 & $\begin{array}{l}\text { Medium } \\
(12-24 \mathrm{~h})\end{array}$ & Hypnotic \\
\hline Chlordiazepoxide & 10 & $\begin{array}{l}\text { Long } \\
(24 \mathrm{~h} \leq)\end{array}$ & Anxiolytic \\
\hline Clobazam & 10 & $\begin{array}{l}\text { Long } \\
(24 \mathrm{~h} \leq)\end{array}$ & Others \\
\hline Clonazepam & 0.25 & $\begin{array}{l}\text { Long } \\
(24 \mathrm{~h} \leq)\end{array}$ & Hypnotic \\
\hline $\begin{array}{l}\text { Clorazepate } \\
\text { Dipotassium }\end{array}$ & 7.5 & $\begin{array}{l}\text { Long } \\
(24 \mathrm{~h} \leq)\end{array}$ & Anxiolytic \\
\hline Cloxazolam & 1.5 & $\begin{array}{l}\text { Long } \\
(24 \mathrm{~h} \leq)\end{array}$ & Anxiolytic \\
\hline Diazepam & 5 & $\begin{array}{l}\text { Long } \\
(24 \mathrm{~h} \leq)\end{array}$ & Others \\
\hline Ethyl Loflazepate & 1.67 & $\begin{array}{l}\text { Long } \\
(24 \mathrm{~h} \leq)\end{array}$ & Anxiolytic \\
\hline Fludiazepam & 0.5 & $\begin{array}{l}\text { Long } \\
(24 \mathrm{~h} \leq)\end{array}$ & Anxiolytic \\
\hline $\begin{array}{l}\text { Flurazepam } \\
\text { Hydrochloride }\end{array}$ & 15 & $\begin{array}{l}\text { Long } \\
(24 \mathrm{~h} \leq)\end{array}$ & Hypnotic \\
\hline Medazepam & 10 & $\begin{array}{l}\text { Long } \\
(24 \mathrm{~h} \leq)\end{array}$ & Anxiolytic \\
\hline Oxazolam & 20 & $\begin{array}{l}\text { Long } \\
(24 \mathrm{~h} \leq)\end{array}$ & Anxiolytic \\
\hline Phenobarbital & 15 & $\begin{array}{l}\text { Long } \\
(24 \mathrm{~h} \leq)\end{array}$ & Others \\
\hline Quazepam & 15 & $\begin{array}{l}\text { Long } \\
(24 \mathrm{~h} \leq)\end{array}$ & Hypnotic \\
\hline Tandospirone Citrate & 25 & $\begin{array}{l}\text { Long } \\
(24 \mathrm{~h} \leq)\end{array}$ & Anxiolytic \\
\hline
\end{tabular}

Table 2

Alternative drugs for BZD.

\begin{tabular}{l}
\hline Escitalopram Oxalate \\
Fluvoxamine Maleate \\
Mianserin Hydrochloride \\
Mirtazapine \\
Paroxetine Hydrochloride Hydrate \\
Quetiapine Fumarate \\
Ramelteon \\
Suvorexant \\
Sertraline Hydrochloride \\
Tandospirone Citrate \\
Trazodone Hydrochloride \\
BZD, Benzodiazepine.
\end{tabular}

more were considered evidence that multi-collinearly existed. The proportional-hazards assumption was assessed using log-minus-log plots. All reported $P$ values are two-tailed and the level of significance was set at $\mathrm{P}<0.05$. Statistical analyses were performed using $\mathrm{R}$ version 3.4.0.

\section{Results}

\subsection{Characteristics and the disposition of patients}

We extracted the data of 92,005 people from the electronic health records, which included outpatients who were prescribed drugs from any clinical department in the hospital during the observational period. Of the total number of outpatients, $8006(8.7 \%)$ were prescribed BZDs at least once; of these, 3639 patients were identified as new BZD users. Upon excluding 169 patients who were less than 18 years old, 3470 patients remained in our cohort (Fig. 1). Demographic and clinical characteristics of our cohort are presented in Table 3 . The mean age \pm standard deviation (SD) was $60 \pm 17.5$ years old, and $50.5 \%$ of the cohort was 65 years old or more. Additionally, $22.8 \%$ of the patients were prescribed BZD by psychiatrists. The mean dosage of BZD \pm SD was $7.2 \pm 8.7 \mathrm{mg}$ of a DZP-equivalent daily dose, and $32.2 \%$ of the cohort belonged to the group with more than $5 \mathrm{mg}$ dosage. Furthermore, $20.3 \%$ of patients had concurrent use of BZD, $64.4 \%$ of patients were prescribed a hypnotic as a type of BZD, and $24.4 \%$ of patients had concurrent use of an alternative drug to BZDs.

\subsection{Tendency to prescribe BZDs}

The tendency to prescribe BZDs for psychiatric patients from March 2004 to September 2016 is shown in Fig. 2. The number of prescriptions containing BZDs decreased gradually from 2722 to 1019 during the whole period that we observed (Fig. 2A). The reduction in these values also occurred as the proportion of patients per 1000 gradually decreased from 992 to 482 during our period of observation (Fig. 2B). Furthermore, we calculated the number of BZDs per a prescription, which decreased slowly from 1.73 to 1.36 (Fig. 3).

\subsection{Proportion of BZD continuation}

The Kaplan-Meier event-free curve, censored at 45-months, describes the time to discontinuation of BZD use; it is shown in Fig. 4. We found that $2901(83.6 \%)$ people were censored. The estimated probabilities of the continuation of BZD use for new BZD users were $90.0 \%$ for 2-month continuation, $86.2 \%$ for 3 -month continuation, $80.7 \%$ for 6 -month continuation, and $71.1 \%$ for 12 -month continuation, respectively. Notably, $57.8 \%$ represented continuation for 36 -months or higher. The median discontinuation time was not calculated because the proportion of the event was less than $50 \%$. 


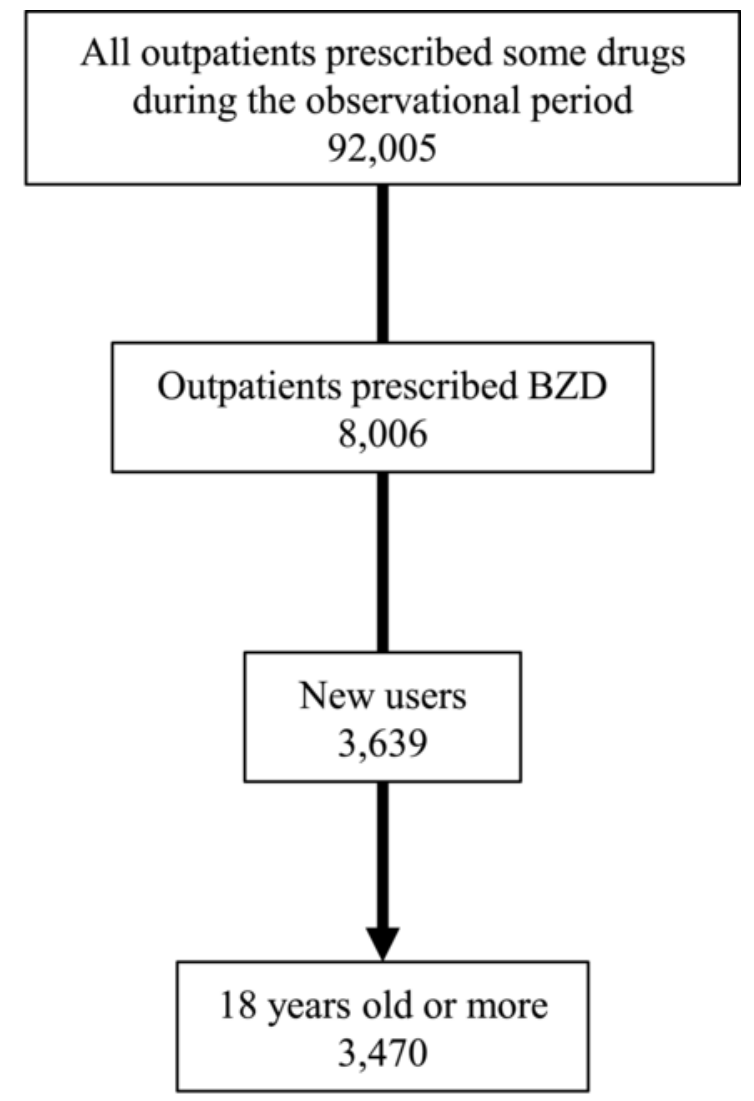

BZD, Benzodiazepine

Fig. 1. The study population.

\subsection{Independent predictors of BZD continuation}

Multivariate Cox regression analysis revealed seven independent predictors (Fig. 5). Continuation of BZDs was significantly associated with age 65 years or greater, psychiatrist-prescribers, dosage of $5 \mathrm{mg}$ or more of a DZP-equivalent daily dose, and concurrent use of BZDs. In contrast, the prescription of hypnotics (rather than only anxiolytics), and concurrent use of antipsychotics or alternative drugs to BZDs were significantly associated with the discontinuation of BZD use. We calculated VIF as a measure of multicollinearity; we found that each VIF did not exceed 10. The proportional-hazards assumption was confirmed through a log-minus-log plot.

\section{Discussion}

In the current study, we investigated the independent predictors of discontinuation of BZD use in our university hospital by extracting data from the electronic health record database, with a new -user design. We found that $8006(8.7 \%)$ of all outpatients at all clinical departments in the hospital were prescribed BZDs during our observational period, and continuation of BZD use for more than 36 months was observed in $57.8 \%$ of 3470 new users. Concurrent use of alternative drugs was an independent predictor of the discontinuation of long-term use of BZDs.

Continuation of BZDs for more than 36 months was observed in $57.8 \%$ of 3470 new users. A previous study investigating the long-term use of BZDs reported that $15.2 \%$ of new BZD-users continued to use BZDs in the first year (Takeshima et al., 2016). The frequency of BZD continuation found in our results was high. The discrepancy between the results of our study and those of the previous study may have
Table 3

Demographic and clinical characteristics of the patients.

\begin{tabular}{|c|c|c|}
\hline \multicolumn{3}{|l|}{ Characteristics $(\mathrm{n}=3470)$} \\
\hline \multicolumn{3}{|l|}{ Sex, no. (\%) } \\
\hline Male & 1360 & $(39.2)$ \\
\hline Female & 2110 & $(60.8)$ \\
\hline \multicolumn{3}{|l|}{ Age, year } \\
\hline Mean (SD) & 60 & (17.5) \\
\hline Range & $18-96$ & \\
\hline \multicolumn{3}{|l|}{ Age group, no. (\%) } \\
\hline $18-45$ & 789 & $(22.7)$ \\
\hline $45-65$ & 928 & $(26.8)$ \\
\hline $65-85$ & 1677 & $(48.3)$ \\
\hline $85 \leq$ & 76 & $(2.2)$ \\
\hline \multicolumn{3}{|l|}{ Medical specialty, no. (\%) } \\
\hline Non-psychiatry & 2679 & $(77.2)$ \\
\hline Psychiatry & 791 & $(22.8)$ \\
\hline \multicolumn{3}{|l|}{ Dosage of BZD, $\mathrm{mg}^{\mathrm{a}}$} \\
\hline Mean (SD) & 7.2 & $(8.7)$ \\
\hline Range & $0.8-120$ & \\
\hline \multicolumn{3}{|c|}{ Dosage of BZD group, no. $(\%)^{\mathrm{a}}$} \\
\hline$\leq 5 \mathrm{mg}$ & 2354 & $(67.8)$ \\
\hline $5 \mathrm{mg}<$ & 1116 & $(32.2)$ \\
\hline \multicolumn{3}{|c|}{ Concurrent use of BZD, no. (\%) } \\
\hline Monotherapy & 2765 & (79.7) \\
\hline Polytherapy & 705 & $(20.3)$ \\
\hline \multicolumn{3}{|c|}{ Direction of initial prescription, no. (\%) } \\
\hline Only at bedtime & 2426 & $(69.9)$ \\
\hline Others & 1044 & $(30.1)$ \\
\hline \multicolumn{3}{|c|}{ Duration of initial prescription, no. (\%) } \\
\hline$<21$ days & 2002 & $(57.7)$ \\
\hline 21 days $\leq$ & 1468 & $(42.3)$ \\
\hline \multicolumn{3}{|c|}{ Half-life of initial BZD, no. $(\%)^{\mathrm{b}}$} \\
\hline Ultra short (<6 h) & 629 & $(18.1)$ \\
\hline Short (6-12 h) & 1768 & $(51.0)$ \\
\hline Medium (12-24 h) & 272 & $(7.8)$ \\
\hline Long $(24 \mathrm{~h} \leq)$ & 801 & $(23.1)$ \\
\hline \multicolumn{3}{|l|}{ Type of BZD, no. $(\%)^{c}$} \\
\hline Hypnotic & 2234 & $(64.4)$ \\
\hline Anxiolytic & 743 & $(21.4)$ \\
\hline Others & 713 & (20.5) \\
\hline \multicolumn{3}{|c|}{ Concurrent psychotropic drug, no. $(\%)^{\mathrm{c}}$} \\
\hline Antidepressants & 770 & $(22.1)$ \\
\hline Antipsychotics & 549 & $(15.8)$ \\
\hline Alternative drug of BZD & 846 & $(24.4)$ \\
\hline
\end{tabular}

BZD, Benzodiazepine; DZP, diazepam.

a Data expressed as the maximal dosage of a DZP equivalent daily dose.

b When patients used more than one BZD with different half-lives, the one with the longest half-life was chosen.

c As some patients receiving no drugs or multiple drugs, the sum is not $100 \%$.

arisen due to a difference in the proportion of elderly patients aged 65 or more. Our current study revealed older age as a significant predictor of the continuation of BZD use, similar to a previous report (Luijendijk et al., 2008; Manthey et al., 2011). Thus, the high frequency of BZD continuation is expected because of a high proportion of older patients in our cohort. Psychiatric prescribers were also a significantly strong predictor of long-term BZD use. This is potentially because the population in the current study contained many patients (22.8\%) whose symptoms tended to be severe, and who were prescribed BZDs by psychiatrists. Although a decrease was observed in the number of prescriptions containing BZDs provided by psychiatrists over the entire experimental period, psychiatric prescribers were found to be a predictor of BZD continuation. This implies that only decreasing the number of prescriptions has no contribution to a reduction in long-term BZD use. Several studies have suggested that general practitioners, rather than psychiatrists, are responsible for writing BZD prescriptions (Cascade and Kalali, 2008; Lagnaoui et al., 2004; Takeshima et al., 2016). This suggestion stems from the observation that half of the general practitioners (47\%) think that patients expect prescriptions, and as many as $18 \%$ think that not writing prescriptions would threaten their doctor- 


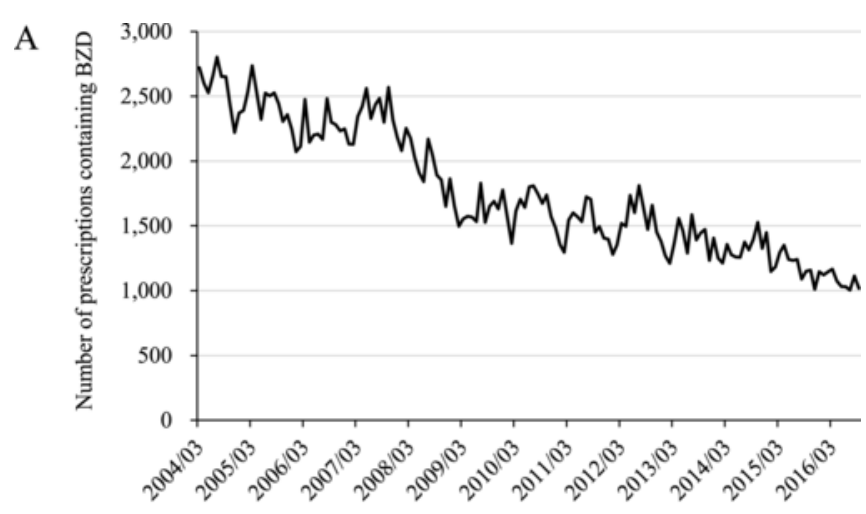

B

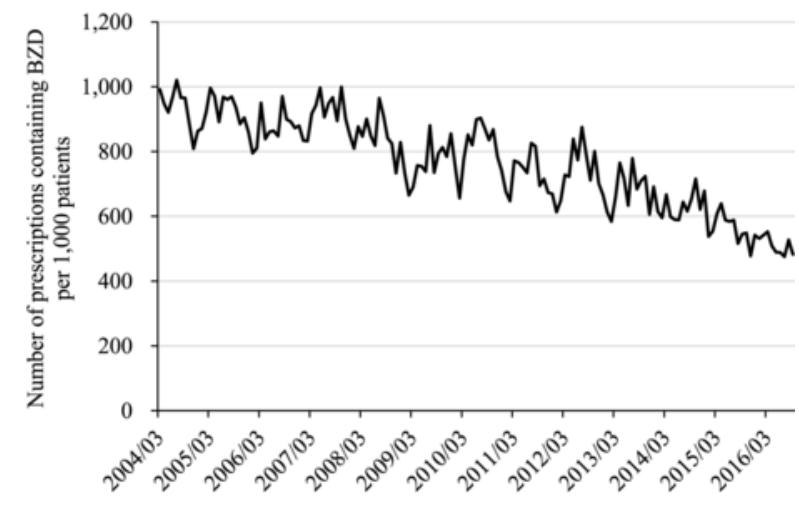

BZD, Benzodiazepine

Fig. 2. Monthly outpatient prescriptions containing BZD in the Department of Psychiatry, from March 2004 to September 2016.

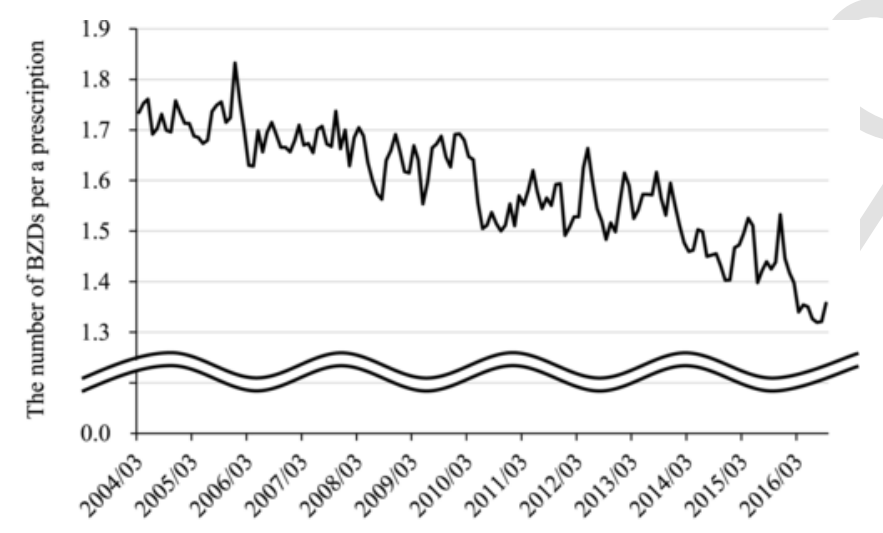

BZD, Benzodiazepine

Fig. 3. The number of BZDs per a prescription of outpatients in the Department of Psychiatry, from March 2004 to September 2016.

patient relationship (Anthierens et al., 2010). Unfortunately, we could not investigate this in our single-center study.

Concurrent use of alternative drugs was found to be an independent predictor of discontinuation of long-term use of BZDs, using multivariate Cox regression analysis. As shown in Table 2, in addition to investigating the influence of antidepressants, anxiolytics, and antipsychotics as alternative hypnotics to BZD, we also tested novel hypnotics such as ramelteon and suvorexant. Our results suggested that replacing BZDs with these alternative hypnotics might lead to discontinuation of BZD use. To initiate the prescription of these alternative drugs to BZD, it is important to consider contraindications and drug interactions. Prescribing alternative drugs could be a countermeasure against long-term BZD use. Along with the results of a previous report (Veronese et al., 2007), our results suggest that concurrent use of antipsychotics is significantly

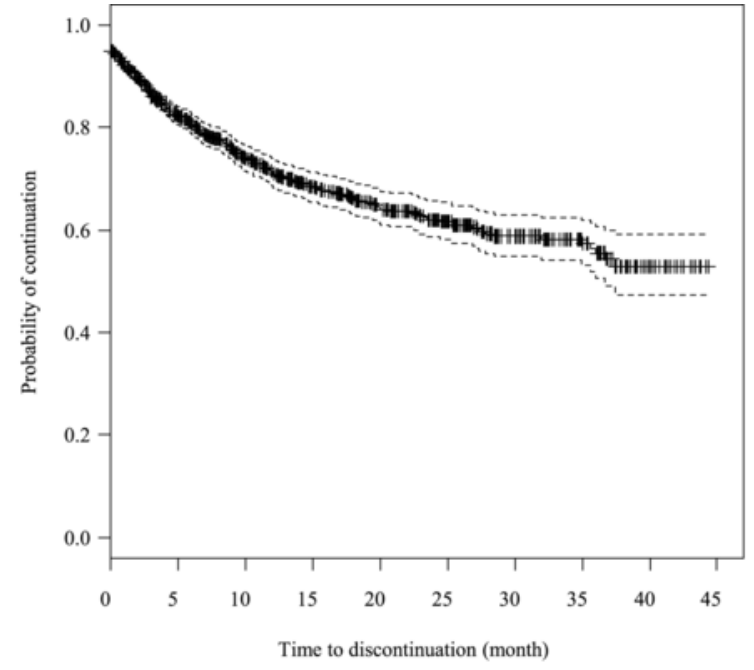

Censored patients are marked as a vertical line. $95 \%$ confidence interval is expressed by broken lines.

Fig. 4. The Kaplan-Meier survival curve describes the time to discontinuation of benzodiazepine.

associated with BZD discontinuation. It has been reported that concurrent use of antipsychotics potentially increases the risk of long-term BZD use (Takeshima et al., 2016), although our current data showed the opposite result. This is potentially because of differences in the analyzed samples. The previous study by Takeshima et al. (2016) analyzed primarily working-age adults and their dependent, therefore, the average age of the sample was 40 years, while our sample had a mean age of 60. In addition, the prior data were derived predominately from clinics, in which many patients with psychiatric diagnoses were diagnosed with anxiety disorder or affective disorder (93.3\%). The current outpatient samples were obtained from a university hospital with a psychiatric inpatient ward; therefore, a considerable proportion of patients with schizophrenia was included in the younger age group. Short-term BZD use is frequently permitted for schizophrenia treatment. This could explain the discontinuation of BZDs in those prescribed antipsychotics. Thus, there is a possibility of reducing the quantity of BZDs and initiating antipsychotics while maintaining hypnotic efficacy. In contrast, it is unknown if the use of antidepressants or BZDs has beneficial net effects, especially in the treatment of schizophrenia (Tiihonen et al., 2012). As previously reported (Isacson, 1997; Kjosavik et al., 2012), we found the quantity of BZD used to be a predictor of the long-term use of BZDs in the present study. BZD polytherapy was a strong predictor of BZD continuation; therefore, it is ethically and practically correct to utilize BZD monotherapy for treatment. One group reported that the type of BZDs used, including either hypnotics or sedatives, or both combined, is not a statistically significant predictor of discontinuation/continuation, as determined through multivariate analysis (Isacson, 1997). Another group reported that hypnotic BZDs are associated with a higher risk of chronic use compared to anxiolytic BZDs (Luijendijk et al., 2008). In the current study, we found that the use of hypnotic BZDs was a statistically significant predictor of discontinuation. Thus, the effect of the type of BZD on long-term use is still controversial.

Contrary to a previous report (Takeshima et al., 2016), the half-life of BZDs was not found to be a predictor of continued use. We think this disagreement is due to the different age ranges of the study population in the two studies. The duration of initial prescription was also not found to be a predictor of continued use. In Japan, BZDs are restricted to a single prescription with a duration of 30 days in order to regulate chronic BZD use; however, it is possible to prescribe BZDs repeatedly, resulting in long-term prescription. This likely renders the 30-day duration of prescription restriction ineffective, and permits BZD continuation. The PMDA (Pharmaceuticals and Medical Devices Agency, a 


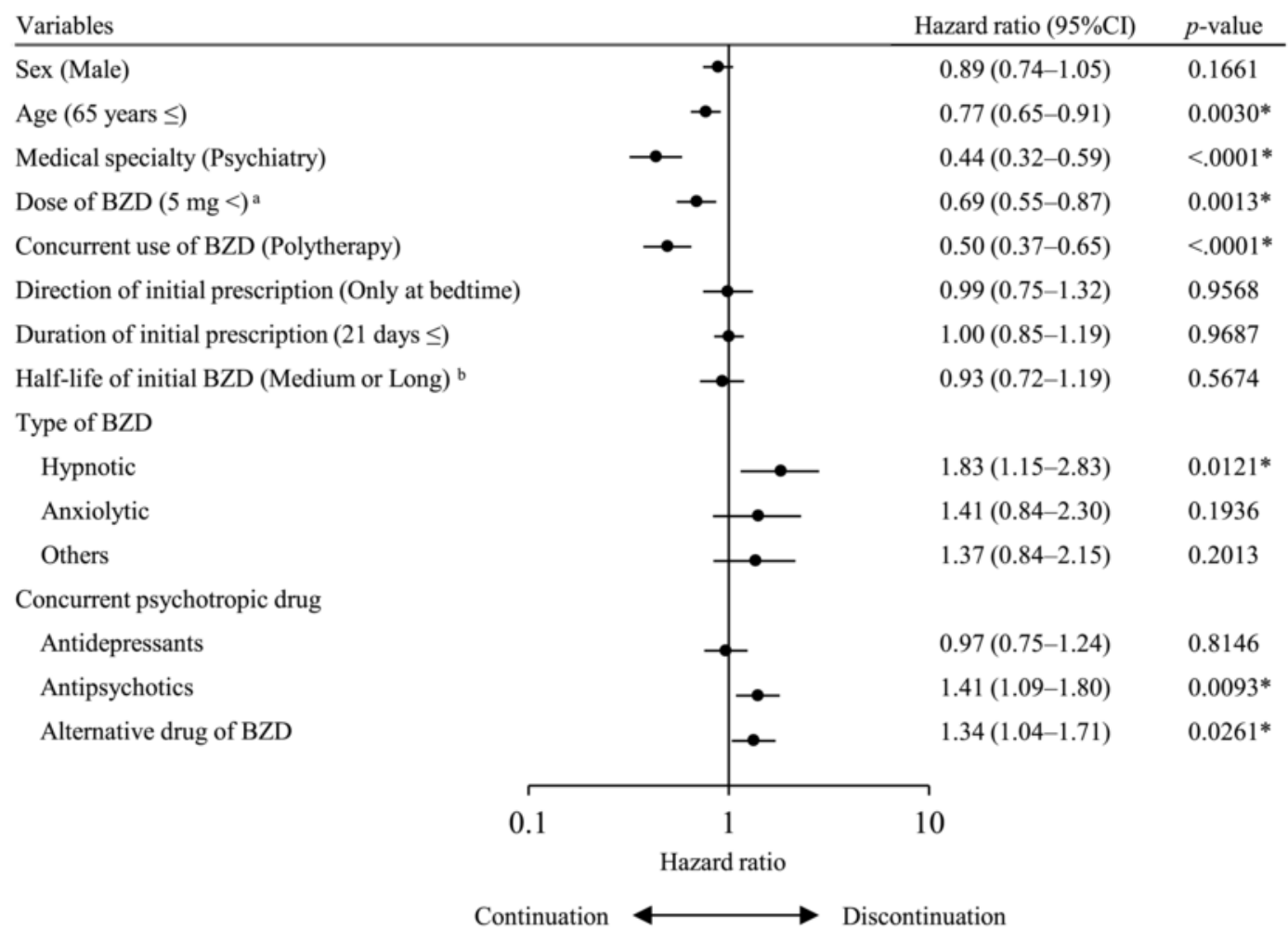

BZD, Benzodiazepine; DZP, diazepam. ${ }^{a}$ Data expressed as the maximal DZP equivalent daily dose. ${ }^{b}$ When patients used more than one kind of BZD with different half-lives, the one with the longest half-life was chosen.

Fig. 5. Independent predictors of BZD continuation.

Japanese regulatory agency), in collaboration with the Japanese Ministry of Health, Labour and Welfare warned to avoid long-term use of BZDs in March 2017 (http://www.pmda.go.jp/files/000217228.pdf), although there exists no punitive legislation in Japan. Other potential predictors have also been surveyed previously. Earlier studies have shown that the use of BZDs is higher in women, and it increases steadily with age (Petitjean et al., 2007; Simon et al., 1996), although, the effect of sex on BZD continuation is still controversial (Taipale et al., 2015). These suggestions are consistent with our results.

Our study is not without limitations. A relatively small sample size was used in our study, compared to other studies based on nationwide claims-databases. There was a lack of prescriptions written by primary care physicians. It is uncertain whether the patients actually took the BZDs prescribed to them, as our data source only provided prescription data from the electronic medical records. However, our dataset is superior to a claims-database with respect to its impartial composition of sex, age, and occupation. We consider that our dataset, containing prescriptions from several clinical departments and many kinds of drugs, is advantageous. The use of data from an unselected, population-based sample of patients may be an important step in avoiding selection bias (Wu et al., 2011).

We conclude that the prescription of alternative drugs to BZDs, as surveyed in the present study, is one of the contributing factors that may help solve the problem of long-term BZD use. Novel hypnotics such as ramelteon and suvorexant are more expensive than BZDs, and antipsychotics have a risk of severe adverse effects, impaired glucose tolerance, neuroleptic malignant syndrome, and hematopathy. Therefore, we currently cannot fully rely on these alternative drugs for treatment. Further studies in form of clinical trials are necessary to clarify the efficacy and safety of alternative drugs to BZDs. This will help us to develop complementary therapies that may be effective without the use of BZDs for disorders such as refractory insomnia.

\section{Conclusion}

This study revealed the factors associated with the long-term use of BZDs, including elderly patients, psychiatrist prescribers, high dosage of BZD, and concurrent use of BZD. In contrast, factors associated with the discontinuation of BZDs included using hypnotic types of BZDs and concurrent use of psychotropic drugs such as antipsychotics or alternative drugs to BZDs. These results suggest that replacing BZDs with other psychotropic drugs, such as antipsychotics, selective serotonin reuptake inhibitors (SSRIs), tetracyclic antidepressants, or novel hypnotics such as ramelteon and suvorexant, may help to avoid long-term use of BZD.

\section{Funding}

This research did not receive any specific grant from funding agencies in the public, commercial, or not-for-profit sectors.

\section{Conflicts of interest}

All authors do not have any relevant conflicts of interest to disclose with respect to this manuscript.

\section{Appendix A. Supplementary data}

Supplementary data related to this article can be found at https:// doi.org/10.1016/j.jpsychires.2017.11.012. 


\section{References}

American Geriatrics Society 2012 Beers Criteria Update Expert Panel, 2012. American Geriatrics Society updated Beers Criteria for potentially inappropriate medication use in older adults. J. Am. Geriatr. Soc. 60, 616-631. https://doi.org/10.1111/j. 1532-5415.2012.03923.x.

Anthierens, S., Pasteels, I., Habraken, H., Steinberg, P., Declercq, T., Christiaens, T., 2010. Barriers to nonpharmacologic treatments for stress, anxiety, and insomnia: family physicians' attitudes toward benzodiazepine prescribing. Can. Fam. Physician 56, e398-406, doi:56/11/e398 (pii).

Barker, M.J., Greenwood, K.M., Jackson, M., Crowe, S.F., 2004. Cognitive effects of long-term benzodiazepine use: a meta-analysis. CNS Drugs 18, 37-48.

Belleville, G., 2010. Mortality hazard associated with anxiolytic and hypnotic drug use in the National Population Health Survey. Can. J. Psychiatry 55, 558-567. https://doi. org/10.1177/070674371005500904.

Bossini, L., Coluccia, A., Casolaro, I., Benbow, J., Amodeo, G., De Giorgi, R., Fagiolini, A., 2015. Off-label trazodone prescription: evidence, benefits and risks. Curr. Pharm. Des. 21, 3343-3351.

Cascade, E., Kalali, A.H., 2008. Use of benzodiazepines in the treatment of anxiety. Psychiatry (Edgmont) 5, 21-22.

Charlson, F., Degenhardt, L., McLaren, J., Hall, W., Lynskey, M., 2009. A systematic review of research examining benzodiazepine-related mortality. Pharmacoepidemiol. Drug Saf. 18, 93-103. https://doi.org/10.1002/pds.1694.

Cloos, J.-M., Ferreira, V., 2009. Current use of benzodiazepines in anxiety disorders. Curr. Opin. Psychiatry 22, 90-95. https://doi.org/10.1097/YCO.0b013e32831a473d.

Cumming, R.G., Le Couteur, D.G., 2003. Benzodiazepines and risk of hip fractures in older people: a review of the evidence. CNS Drugs 17, 825-837.

Fisher, J., Sanyal, C., Frail, D., Sketris, I., 2012. The intended and unintended consequences of benzodiazepine monitoring programmes: a review of the literature. J. Clin. Pharm. Ther. 37, 7-21. https://doi.org/10.1111/j.1365-2710.2011.01245.x.

Holbrook, A.M., Crowther, R., Lotter, A., Cheng, C., King, D., 2000. Meta-analysis of benzodiazepine use in the treatment of insomnia. CMAJ 162, 225-233.

Iaboni, A., Bronskill, S.E., Reynolds, K.B., Wang, X., Rochon, P.A., Herrmann, N., Flint, A., 2016. Changing pattern of sedative use in older adults: a population-based cohort study. Drugs Aging 33, 523-533. https://doi.org/10.1007/s40266-016-0380-3.

Inada, T., Inagaki, A., 2015. Psychotropic dose equivalence in Japan. Psychiatry Clin. Neurosci 69, 440-447. https://doi.org/10.1111/pcn.12275.

Isacson, D., 1997. Long-term benzodiazepine use: factors of importance and the development of individual use patterns over time - a 13-year follow-up in a Swedish community. Soc. Sci. Med. 44, 1871-1880. https://doi.org/10.1016/ S0277-9536(96)00296-1.

Ishigooka, J., Sugiyama, T., Suzuki, M., Kobayashi, K., Takeuchi, H., Murasaki, M., 1998. Survival analytic approach to long-term prescription of benzodiazepine hypnotics. Psychiatry Clin. Neurosci. 52, 541-545. https://doi.org/10.1046/j.1440-1819.1998. 00422.x.

Kato, K., Hirai, K., Nishiyama, K., Uchikawa, O., Fukatsu, K., Ohkawa, S., Kawamata, Y., Hinuma, S., Miyamoto, M., 2005. Neurochemical properties of ramelteon (TAK-375), a selective MT1/MT2 receptor agonist. Neuropharmacology 48, 301-310. https://doi. org/10.1016/j.neuropharm.2004.09.007.

Kjosavik, S.R., Ruths, S., Hunskaar, S., 2012. Use of addictive anxiolytics and hypnotics in a national cohort of incident users in Norway. Eur. J. Clin. Pharmacol. 68, 311-319. https://doi.org/10.1007/s00228-011-1124-2.

Kripke, D.F., Langer, R.D., Kline, L.E., 2012. Hypnotics' association with mortality or cancer: a matched cohort study. BMJ Open 2, e000850. https://doi.org/10.1136/ bmjopen-2012-000850.

Lader, M., 2011. Benzodiazepines revisited-will we ever learn?. Addiction 106, 2086-2109. https://doi.org/10.1111/j.1360-0443.2011.03563.x.

Lader, M.H., Petursson, H., 1981. Benzodiazepine derivatives-side effects and dangers. Biol. Psychiatry 16, 1195-1201.

Lagnaoui, R., Depont, F., Fourrier, A., Abouelfath, A., Bégaud, B., Verdoux, H., Moore, N., 2004. Patterns and correlates of benzodiazepine use in the French general population. Eur. J. Clin. Pharmacol. 60, 523-529. https://doi.org/10.1007/s00228-004-0808-2.

Luijendijk, H.J., Tiemeier, H., Hofman, A., Heeringa, J., Stricker, B.H.C., 2008. Determinants of chronic benzodiazepine use in the elderly: a longitudinal study. Br. J. Clin. Pharmacol. 65, 593-599. https://doi.org/10.1111/j.1365-2125.2007.03060.x.

Manthey, L., Giltay, E.J., van Veen, T., Neven, A.K., Zitman, F.G., Penninx, B.W.J.H., 2011. Determinants of initiated and continued benzodiazepine use in The Nether- lands study of depression and anxiety. J. Clin. Psychopharmacol. 31, 774-779. https:// doi.org/10.1097/JCP.0b013e3182362484.

Martin, J.L.R., Sainz-Pardo, M., Furukawa, T.A., Martín-Sánchez, E., Seoane, T., Galán, C., 2007. Benzodiazepines in generalized anxiety disorder: heterogeneity of outcomes based on a systematic review and meta-analysis of clinical trials. J. Psychopharmacol. 21, 774-782. https://doi.org/10.1177/0269881107077355.

McLeod, P.J., Huang, A.R., Tamblyn, R.M., Gayton, D.C., 1997. Defining inappropriate practices in prescribing for elderly people: a national consensus panel. CMAJ 156, 385-391.

Panneman, M.J.M., Goettsch, W.G., Kramarz, P., Herings, R.M.C., 2003. The costs of benzodiazepine-associated hospital-treated fall Injuries in the EU: a Pharmo study. Drugs Aging 20, 833-839.

Pariente, A., Dartigues, J.-F., Benichou, J., Letenneur, L., Moore, N., Fourrier-Réglat, A., 2008. Benzodiazepines and injurious falls in community dwelling elders. Drugs Aging $25,61-70$.

Passaro, A., Volpato, S., Romagnoni, F., Manzoli, N., Zuliani, G., Fellin, R., 2000. Benzodiazepines with different half-life and falling in a hospitalized population: the GIFA study. Gruppo Italiano di Farmacovigilanza nell'Anziano. J. Clin. Epidemiol. 53, 1222-1229.

Petitjean, S., Ladewig, D., Meier, C.R., Amrein, R., Wiesbeck, G.A., 2007. Benzodiazepine prescribing to the Swiss adult population: results from a national survey of community pharmacies. Int. Clin. Psychopharmacol. 22, 292-298. https://doi.org/10.1097/ YIC.0b013e328105e0f2.

Pfeiffer, P.N., Ganoczy, D., Zivin, K., Valenstein, M., 2011. Benzodiazepines and adequacy of initial antidepressant treatment for depression. J. Clin. Psychopharmacol. 31, 360-364. https://doi.org/10.1097/JCP.0b013e318217b4c4.

Schroeck, J.L., Ford, J., Conway, E.L., Kurtzhalts, K.E., Gee, M.E., Vollmer, K.A., Mergenhagen, K.A., 2016. Review of safety and efficacy of sleep medicines in older adults. Clin. Ther. 38, 2340-2372. https://doi.org/10.1016/j.clinthera.2016.09.010.

Shorr, R.I., Robin, D.W., 1994. Rational use of benzodiazepines in the elderly. Drugs Aging 4, 9-20.

Simon, G.E., VonKorff, M., Barlow, W., Pabiniak, C., Wagner, E., 1996. Predictors of chronic benzodiazepine use in a health maintenance organization sample. J. Clin. Epidemiol. 49, 1067-1073. https://doi.org/10.1016/0895-4356(96)00139-4.

Smink, B.E., Egberts, A.C.G., Lusthof, K.J., Uges, D.R.A., de Gier, J.J., 2010. The relationship between benzodiazepine use and traffic accidents: a systematic literature review. CNS Drugs 24, 639-653. https://doi.org/10.2165/11533170-000000000-00000.

Taipale, H., Koponen, M., Tanskanen, A., Tolppanen, A.-M., Tiihonen, J., Hartikainen, S., 2015. Long-term use of benzodiazepines and related drugs among community-dwelling individuals with and without Alzheimer's disease. Int. Clin. Psychopharmacol. 30, 202-208. https://doi.org/10.1097/YIC.0000000000000080.

Takeshima, N., Ogawa, Y., Hayasaka, Y., Furukawa, T.A., 2016. Continuation and discontinuation of benzodiazepine prescriptions: a cohort study based on a large claims database in Japan. Psychiatry Res. 237, 201-207. https://doi.org/10.1016/j.psychres. 2016.01.040.

Tiihonen, J., Suokas, J.T., Suvisaari, J.M., Haukka, J., Korhonen, P., 2012. Polypharmacy with antipsychotics, antidepressants, or benzodiazepines and mortality in schizophrenia. Arch. Gen. Psychiatry 69, 476-483. https://doi.org/10.1001/archgenpsychiatry. 2011.1532.

Urru, S.A.M., Pasina, L., Minghetti, P., Giua, C., 2015. Role of community pharmacists in the detection of potentially inappropriate benzodiazepines prescriptions for insomnia. Int. J. Clin. Pharm. 37, 1004-1008. https://doi.org/10.1007/s11096-015-0166-4.

Veronese, A., Garatti, M., Cipriani, A., Barbui, C., 2007. Benzodiazepine use in the real world of psychiatric practice: low-dose, long-term drug taking and low rates of treatment discontinuation. Eur. J. Clin. Pharmacol. 63, 867-873. https://doi.org/10.1007/ s00228-007-0341-1.

Vicens, C., Bejarano, F., Sempere, E., Mateu, C., Fiol, F., Socias, I., Aragonès, E., Palop, V., Beltran, J.L., Piñol, J.L., Lera, G., Folch, S., Mengual, M., Basora, J., Esteva, M., Llobera, J., Roca, M., Gili, M., Leiva, A., 2014. Comparative efficacy of two interventions to discontinue long-term benzodiazepine use: cluster randomised controlled trial in primary care. Br. J. Psychiatry 204, 471-479. https://doi.org/10.1192/bjp.bp.113. 134650.

Wu, C.-S., Lin, Y.-J., Liu, S.-K., 2011. Benzodiazepine use among patients with schizophrenia in Taiwan: a nationwide population-based survey. Psychiatr. Serv. 62, 908-914. https://doi.org/10.1176/ps.62.8.pss6208_0908. 